\title{
Palatalização de /l/: atuação de fatores sociais
}

Palatalization of / L/: THE ROLE OF SOCIAL FACTORS

Marilucia Barros Oliveira*

Resumo: Trata o presente estudo da variação de /1/ em posição prevocálica no Português Brasileiro (PB), mais especificamente da palatalização que ocorre diante de segmentos altos anteriores quando seguem esse fonema. Os dados são oriundos do projeto Atlas Linguístico do Pará (ALiPA). Neste artigo, será avaliada apenas a atuação de fatores sociais. No sentido de fomentar o refinamento da análise da atuação desses fatores, serão apresentados também resultados referentes ao cruzamento dos grupos de fatores selecionados. Os resultados serão discutidos levando-se em consideração os pressupostos da Sociolinguísitica Variacionista, informações registradas durante a coleta de dados na comunidade pesquisada e resultados de estudos sociolinguísticos publicados no Brasil. Os dados revelam que a palatalização de /1/, na cidade pesquisada, encontra-se em estágio bastante avançado e que se constitui tendência em Itaituba-PA, diferentemente do que Oliveira (2010) detectou para várias localidades no Brasil, especialmente para o Nordeste e Sul do país. Os resultados também apontam a importante atuação da escolaridade sobre a variação em estudo.

Palavras-chave: Variação. Português Brasileiro. Palatalização.

Abstract: This study deals with the variation of $/ 1 /$ in pre-vowel position in Brazilian Portuguese (BP), more specifically the palatalization that occurs before high anterior segments, when following this phoneme. The data come from the Linguistic Atlas project of Pará (ALiPA). In this article, only the role of social factors will be analyzed. In order to foster the refinement of the

* Doutora em Linguística pela Universidade Federal de Alagoas (2007). Professora Associada I da Universidade Federal do Pará. Contato: mariluci@ufpa.br. 
performance analysis of these factors, results for the groups matching of selected factors will also be presented. The findings will be discussed taking into account the principles of the Variationist Sociolinguistics, the information registered during the data collecting process in the studied community as well as the findings of other sociolinguistics studies carried out in Brazil. The data show that the palatalization of $/ 1 /$ in the city where the research took place, is in quite advanced stage and becomes a trend in Itaituba-PA, unlike what Oliveira (2010) found in several localities in Brazil, especially for the Northeast and South of the country. Results also point to the important role of education on the variation in study.

Keywords: Change. Brazilian Portuguese. Palatalization.

\section{Introdução}

Há, atualmente, um fenômeno linguístico que tem causado muita curiosidade quando se trata de algumas especificidades linguísticas no Português do Brasil (PB). Trata-se da realização palatalizada de /1/, em outras palavras, casos em que se tem [' $\left.1^{\mathrm{j}} \mathrm{v} r \mathrm{~J}\right]$ ou ['Kivru] para livro, em que /1/ passa a [i] ou [K]. A palatalização das oclusivas alveolares /t/ e /d/ já foi amplamente atestada no espaço brasileiro, entretanto, a palatalização da lateral alveolar /1/, atestada na passagem do Latim para o Português, parece constituir-se em um fenômeno ainda pouco estudado e produtivo no PB, e que já começou a se difundir na região Norte do país.

Oliveira (2007) assinala, a partir de pesquisa realizada nos atlas linguísticos regionais e estaduais produzidos no Brasil, que a realização palatalizada de /1/ diante de [i] é praticamente restrita ao espaço paraense. A consulta a outros trabalhos sobre a palatalização revelou também que, diferentemente da palatalização de /t/ e /d/, a palatalização de /1/ não foi praticamente estudada no Brasil. Isso é explicável. A lateral alveolar /1/ foi registrada no PB, excetuando-se o estado do Pará, como lateral alveolar [1] quase categoricamente, de acordo com os estudos realizados até a década de 1990.

Por conta da baixa frequência do fenômeno, alguns estudos apresentam a palatalização de /1/ como um fenômeno esporádico que recebe apenas 


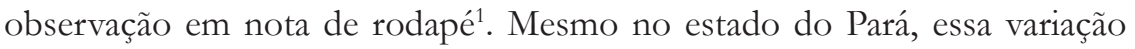
não recebeu um estudo detalhado até 2007, mas apenas menções de sua realização. A referida palatalização, segundo Oliveira (2007), não atestada no Atlas Linguístico do Paraná (AGUILERA, 1994), foi registrada, embora timidamente, em algumas áreas desse estado no Atlas Linguístico-etnográfico da Região Sul, publicado em 2002. Nos dados do ALiPA (coletados na década de 90), essa variação foi encontrada de forma produtiva na Mesorregião Nordeste do Pará ${ }^{2}$. Esse fenômeno parece fazer, no espaço paraense, um caminho bem diferente do que é verificado no restante do Brasil quando se comparam esses resultados aos registrados em estudos anteriores ao de Oliveira (2007). Dessa forma, merece atenção especial.

\section{Metodologia}

\subsection{A comunidade pesquisada: Itaituba-PA}

Itaituba fica a $891 \mathrm{~km}$ da capital do estado do Pará, Belém. Localizada à margem esquerda do Rio Tapajós, como veremos na Figura 1, pertence à Mesorregião Sudoeste Paraense e Microrregião de Itaituba.

A cidade de Itaituba começou como um pequeno aglomerado, popularmente conhecido como Beiradão, na margem do Rio Tapajós. Como a maioria dos municípios paraenses, a cidade de Itaituba também tem um nome de origem tupi, que significa "lugar dos pedregulhos". Entre os indígenas era comum se denominarem lugares tomando-se por base aspectos visuais, físicos do lugar que nomeavam. À margem esquerda do Tapajós existem até hoje pequenas pedras (seixos). Conforme dados do PRIMAZ (Programa de Integração dos Municípios da Amazônia), a origem da cidade está ligada à conquista do Rio Tapajós pelos portugueses.

${ }^{1}$ Isso ocorreu antes da publicação dos estudos de Oliveira (2007) e da publicação do Atlas Linguísitico do Brasil (2014).

2 Para consulta à pesquisa bibliográfica sobre a palatalização de /1/ no Brasil, consultar Oliveira et al. (2009). 
Essa conquista foi impulsionada pela necessidade de defenderem o rio Amazonas dos invasores estrangeiros, que tentaram conquistar o estuário amazônico. Para combater tais invasões foram organizadas várias expedições pelo governo português, dentre as quais uma comandada por Francisco Caldeira Castelo Branco em 1616 [...] para Itaituba a expedição mais importante foi comandada pelo capitão Pedro Teixeira, que, em 1626, pela primeira vez atingiu o rio Tapajós. Ao penetrar pelo mesmo, no local hoje conhecido como Alter do Chão, manteve o primeiro contato amigável com os naturais da região. Em 1639 o capitão Pedro Teixeira voltou com nova expedição, adentrou o rio Tapajós e verificou, entre outras coisas, a sua franca navegabilidade, por uma grande extensão (BRASIL, 1996, p. 3).

Depois que essa última expedição descobriu a possibilidade de navegação do rio, chegaram os jesuítas com o propósito de catequizar os índios. Assim, Francisco da Costa Falcão construiu um forte, bem como aldeamentos que foram bastante produtivos principalmente durante os anos compreendidos entre 1742 e 1747 (Brasil, 1996).

\subsubsection{Aspectos geográficos}

A cidade de Itaituba está localizada na porção sul da Amazônia Oriental, mais precisamente na região Sudoeste do Pará. É uma das dez maiores cidades do estado. Está situada na região conhecida como Zona Fisiográfica do Tapajós. Limita-se, ao norte, com o município de Aveiros; ao sul, com os municípios de Jacareacanga e Novo Progresso; a leste, com os municípios de Trairão, Altamira e Rurópolis; a oeste, com o estado do Amazonas. Na Figura 1 podem-se visualizar esses limites dentro do espaço estadual: 


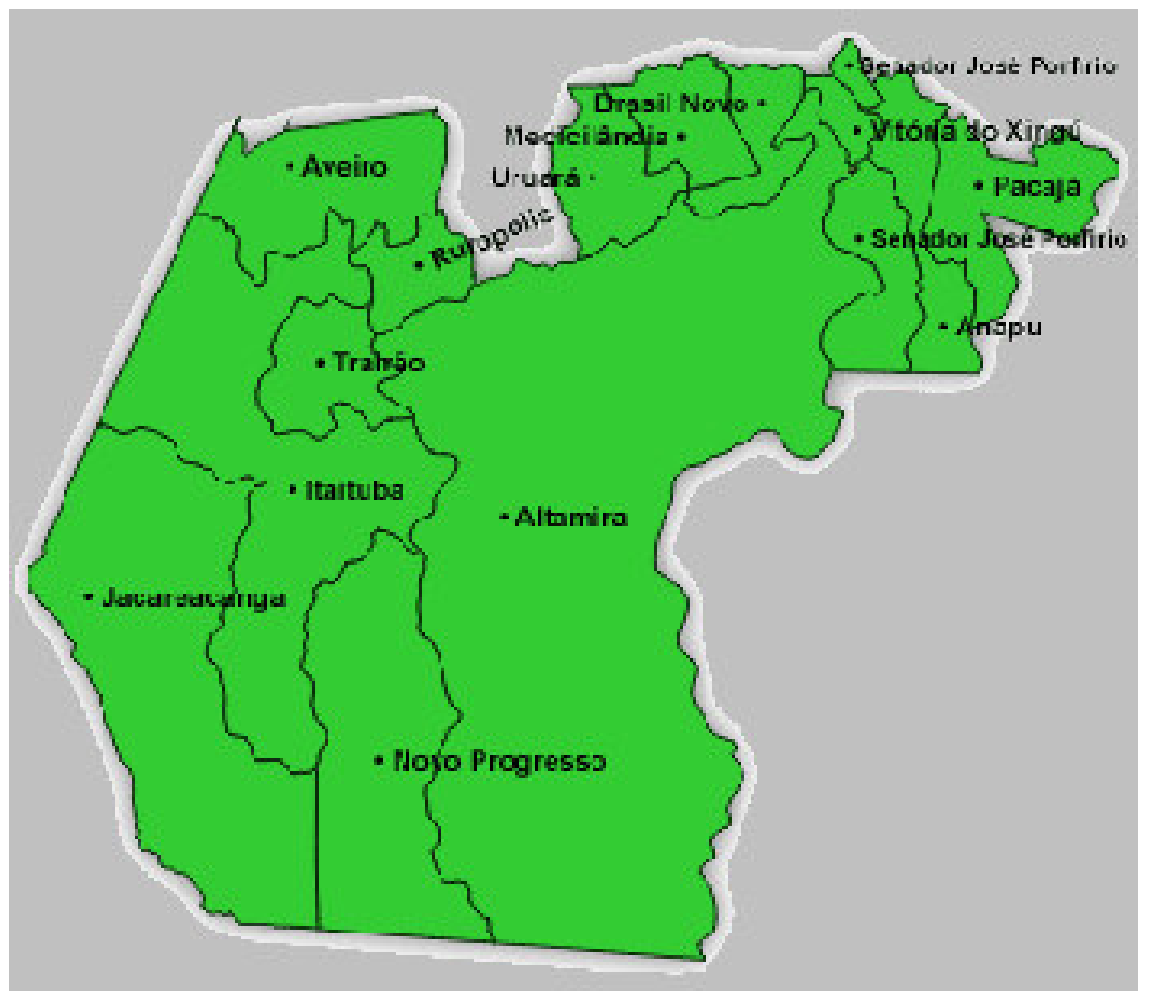

Fonte: <http://bit.do/cWrVm>.

Figura 1 - Localização e limites de Itaituba-PA

Itaituba fica localizada às margens do Tapajós, rio pelo qual é banhada em 95\% de sua extensão; sendo no restante banhada pelo rio Amana. Sua altitude é de ordem de $45 \mathrm{~m}$. Apresenta relevo ondulado, mas não muito elevado. Seu clima é quente e úmido, com duas estações definidas: seca, que vai de junho a novembro; chuvosa, que começa em dezembro e se estende até o mês de maio. Sua vegetação é caracterizada pelas florestas tropicais: densa e aberta.

Itaituba era considerada, até 1993, o município mais extenso do Pará e um dos maiores do mundo. A partir desse ano, foi dividido em três outros municípios, a saber: Jacareacanga, Novo Progresso e Trairão, ficando com uma extensão de $62.565 \mathrm{~km}^{2}$, ainda bastante significativa. 


\subsubsection{Aspectos populacionais}

Por volta de 1958, aconteceu, em Itaituba, uma grande corrente migratória, devido à extração do ouro no Rio Tropas. Essa migração desencadeou o maior índice demográfico já conhecido no estado do Pará e foi responsável por uma grande miscigenação racial. Dentre as causas dessa migração estava a necessidade de mão de obra especializada para trabalhar no extrativismo do ouro e, é claro, a corrida pelo ouro, encabeçada principalmente por maranhenses e cearenses. O grande fluxo migratório ocorrido nas décadas de 70 e 80 no país, principalmente na Amazônia Legal, é atribuído, por Miranda et al. (1997), à busca desordenada pelo ouro motivada, dentre outros, pelo desemprego nas grandes cidades e pela situação da seca no Nordeste.

Durante a coleta de dados para construção deste trabalho, pôde-se perceber quão mesclada é a população de Itaituba. Houve momentos em que foi extremamente difícil encontrar um indivíduo que não tivesse naturalidade nordestina, especialmente maranhense. Isso, por sua vez, é explicável. Segundo Miranda et al. (1997), a maioria dos garimpeiros do Brasil advém da região Nordeste, e 31,67\% deles são maranhenses. Os autores assinalam que mais de 53\% desses maranhenses atuam na região Amazônica. Observa ainda que, desses 53\%, 49,11\% atuam no estado do Pará.

Segundo o Instituto Brasileiro de Geografia e Estatística (IBGE), até o final da década de 1960, podia-se verificar certo equilíbrio entre o número de homens e mulheres no município de Itaituba, bem como a estabilidade no crescimento demográfico. Atestou-se até que, na década de 1970, houve certa diminuição no crescimento da população em relação à década de 1960. O censo referente a essa década demonstrava que a maior parte da população se concentrava na zona rural. A proporção era igual a 10:1. Entretanto, nas últimas décadas houve uma explosão demográfica no município, que deve ter sua causa na corrida pelo ouro, tendo como principais migrantes maranhenses e cearenses. O censo de 1991 mostra que o processo migratório continuou e que, nesse ano, a cidade chegou ao número de 116.541 habitantes; sendo maior o número de homens que de mulheres. Atualmente, devido à crise na atividade garimpeira, grande parte da população itaitubense concentra-se na zona rural. 


\subsection{Tratamento dos dados}

Foram submetidas ao pacote computacional VARBRUL variáveis linguísticas e sociais que constituíram grupos de fatores em relação aos quais foram emitidos pesos relativos. Entretanto, como já foi dito, aqui serão avaliados apenas os fatores sociais. A metodologia utilizada na coleta de dados teve por objetivo a construção de um corpus que representasse ou, pelo menos, que fosse uma amostra representativa significativa do falar da localidade a que pertencem os informantes. Daí a opção de se trabalhar com 36 informantes, um número considerado elevado de certo ponto de vista, mas que, na verdade, não o é quando se leva em consideração a extensão e população da cidade de Itaituba. Esse número sugere trabalho árduo para a construção do corpus, mas, por outro lado, dá mais confiabilidade à pesquisa. Além disso, a própria natureza estatística adotada nesta pesquisa exige a adoção desse critério. Os colaboradores foram estratificados de acordo com o Quadro 1.

Depois de coletados, selecionados e transcritos, os dados foram codificados no editor do Varbrul, checados e preparados para serem submetidos ao Makecell, programa que forneceu as frequências referentes a cada fator. Esses resultados foram denominados intermediários, computando 1.545 dados. Feitos os ajustes de correção dos arquivos intermediários, obteve-se 1.245 dados que foram submetidos ao programa de regra variável, o IVARB, programa do pacote computacional VARBRUL que realiza rodadas binárias. O Thresohold, margem de erro com o qual o programa trabalha, é igual a ,05. Quando o nível de significância está abaixo desse valor, os pesos relativos fornecidos pelo programa são estatisticamente significativos, pois estão dentro da margem de erro com a qual o programa trabalha. O nível de significância da rodada em análise foi igual a .016. Cabe ressaltar que os dados fornecidos por esse programa têm significado estatístico, cabendo ao pesquisador a avaliação linguística dos resultados obtidos.

A seguir, serão apresentados os resultados referentes aos dois grupos de fatores sociais selecionados: escolaridade e sexo, bem como os pesos relativos gerados a partir de seu cruzamento. Considera-se a palatalização a aplicação da regra. 
Quadro 1 - Estratificação social dos informantes

\begin{tabular}{|c|c|c|}
\hline $\begin{array}{c}1^{a} \text { Faixa etária } \\
15-25 \text { anos }\end{array}$ & Homens & Mulheres \\
\hline & Escolaridade & Escolaridade \\
\hline & 2 não escolarizados & 2 não escolarizados \\
\hline & $21^{\circ}$ grau & $21^{\circ} \mathrm{grau}$ \\
\hline & $22^{\circ}$ grau & $22^{\circ}$ grau \\
\hline \multirow[t]{5}{*}{$\begin{array}{c}2^{a} \text { Faixa etária } \\
26-45 \text { anos }\end{array}$} & Homens & Mulheres \\
\hline & Escolaridade & Escolaridade \\
\hline & 2 não escolarizados & 2 não escolarizados \\
\hline & $21^{\circ}$ grau & $21^{\circ}$ grau \\
\hline & $22^{\circ}$ grau & $22^{\circ}$ grau \\
\hline \multirow[t]{5}{*}{$\begin{array}{c}3^{a} \text { Faixa etária } \\
\text { A partir de } \\
46 \text { anos }\end{array}$} & Homens & Mulheres \\
\hline & Escolaridade & Escolaridade \\
\hline & 2 não escolarizados & 2 não escolarizados \\
\hline & $21^{\circ}$ grau & $21^{\circ}$ grau \\
\hline & $22^{\circ} \mathrm{grau}$ & $22^{\circ}$ grau \\
\hline
\end{tabular}




\section{Apresentação e Discussão dos Resultados}

Para o estudo quantitativo da palatalização versus não palatalização de /1/ foram analisados 1.245 dados, mas, ao todo, foram analisados 4.897 dados, no sentido de se avaliar se a palatalização ocorreria em outro contexto que não fosse o de vogais altas anteriores, como referiu Bath (1978), ou se seria motivada por segmento alto anterior em posição precedente à variável, caracterizando-se, assim, como uma regra regressiva, tal como se detectou nos falares nordestinos (MOTA, 1995). Não foram encontrados casos de palatalização que não fosse diante de vogais altas anteriores.

Apesar de terem sido encontradas cinco variantes para /1/, aqui serão analisados dados de palatalização versus não palatalização. Isso se deve ao fato de a baixa ocorrência de [j] e [ø] não recomendarem uma análise quantitativa. $[K]$ e $[1]$ constituíram uma única variante, dada a proximidade e semelhança articulatória entre elas. Essas variantes indicam algum grau de palatalização. Elas foram representadas por [K], que | põe-se à variante alveolar [1]. Tem-se palatalização versus não palatalização.

Dos sete grupos de fatores instituídos, excetuando o grupo da variável dependente, um foi retirado das rodadas, o grupo de fatores contexto precedente. Dos submetidos ao programa de regra variável, quatro foram selecionados. São eles, de acordo com a ordem de seleção: escolaridade, gênero, contexto seguinte e posição na palavra. Os grupos não selecionados foram acento e idade.

Os grupos selecionados foram também os não selecionados. Obtevese, dessa forma, uma seleção que apresenta distribuição complementar. Em termos de stepup e stepdown $n^{3}$ tem-se uma rodada ideal. A pequena gradiência entre os pesos relativos fornecidos nos diferentes níveis também confirma esse dado.

\footnotetext{
O stepup seleciona as variáveis significantes para a aplicação da regra. O stepdown faz procedimento inverso com o fim de avaliar se os grupos selecionados foram também não selecionados. Esse tipo de resultado caracteriza uma distribuição complementar na análise estatística. A seleção e não seleção concomitante de uma determinada variável indicam que há sobreposição de fatores, ou seja, que não estão bem definidos, devendo, o pesquisador, realizar os procedimentos necessários à solução desse inconveniente.
} 


\subsection{Atuação da variável escolaridade sobre a variação de /l/}

Os resultados referentes ao grupo de fatores escolaridade apontam $[K]$ como uma variante não estigmatizada. A seguir, estão dispostos os pesos relativos que confirmam isso.

Tabela 1 - Variável escolaridade

\begin{tabular}{ccc}
\hline Fatores & Ocorrências & P.Relativo \\
\hline Não escolarizados & $585 / 420$ & .33 \\
Ensino fundamental & $544 / 469$ & .54 \\
Ensino médio & $386 / 356$ & .69 \\
Input & - & .86 \\
\hline
\end{tabular}

A teoria da mudança linguística pressupõe que as modificações que ocorrem em dada língua não podem ser atribuídas ao acaso. Assim, cabe ao estudioso da língua indicar quais são os fatores que estão envolvidos nessas modificações.

A palatalização de /1/ é entendida no presente estudo como uma variante inovadora, porém não estigmatizada no espaço itaitubense. Os resultados obtidos para os fatores que compõem o grupo de fatores escolaridade confirmam esse ponto de vista. Os mais escolarizados receberam peso relativo mais alto. Tem-se .69, para os falantes do Ensino Médio; .54, para os do Ensino Fundamental e .33, para os falantes não escolarizados. Esses últimos foram os únicos que inibiram a regra.

Os falantes com Ensino Médio favoreceram significativamente a aplicação da regra. Os indivíduos que têm o ensino fundamental também a favoreceram, mas esse favorecimento não é tão significativo quanto o que se percebe para os falantes que têm Ensino Médio. 
Com base nos pesos relativos fornecidos pelo programa de regra variável, poder-se-ia propor uma escala, para a variável em análise, em que mais escolaridade é proporcional a mais probabilidade de aplicação da regra (PAL). Tem-se uma escala linear em que a palatalização vai se fortalecendo em direção a mais escolaridade, conforme se pode visualizar no esquema abaixo.

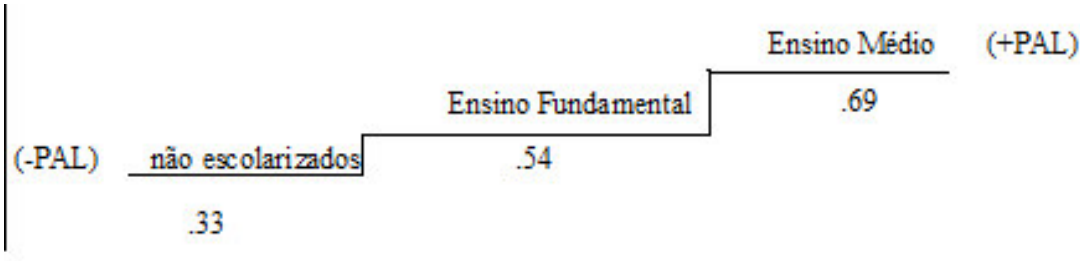

Figura 2 - Probabilidade de aplicação da regra de acordo com a escolaridade

Os dados estatísticos permitem inferir que a variante palatalizada constitui-se na tendência no falar de Itaituba. Dois argumentos o corroboram. Em um processo de mudança em que uma variante adquire significado social a correção social aberta é esporádica, pois os falantes substituem a norma de prestígio pelo vernáculo básico. Quando da realização da coleta de dados na cidade de Itaituba, nenhum dos falantes recorreu à correção do uso da forma palatalizada. Talvez isso indique que $[K]$ tem uma representação social dentro dessa comunidade linguística.

Outro dado tem a ver com o crescimento gradativo da escolarização nessa cidade, especialmente na zona urbana. Ainda durante a coleta mencionada, houve bastante dificuldade para encontrar indivíduos que não apresentassem baixa ou nenhuma escolaridade. Mais escolaridade, de acordo com os pesos relativos, indica maior ocorrência do fenômeno. Se a falta de escolaridade está sendo diminuída na cidade, é provável que haja uma redução ainda maior na ocorrência da variante não palatalizada [1].

Possivelmente esse resultado está relacionado à avaliação que os falantes fazem do uso dessa variante (OLIVEIRA, 2010). A palatalização parece constituir-se em marca do falar itaitubense, bem como do falar da zona 
urbana. Apresenta, assim, certo status social. Já a variante alveolar parece estar ligada à fala do imigrante nordestino, mais especificamente do garimpeiro que, como se verá adiante, parece sofrer certo estigma social em função da atividade que desenvolve.

De acordo com Weinreich, Labov e Herzog (1968), Bloomfield (1933) assinala que um determinado modelo talvez seja imitado em função de seu prestígio. Completam que não é só esse aspecto que está envolvido na proliferação de um determinado traço linguístico. Há relações mais complexas envolvidas em uma mudança linguística. As escolhas, de acordo com os autores, estão ligadas a representações sociais. A escolha cumpre papéis sociais e muda de acordo com a mudança na estrutura social, explicam. A produtiva aplicação da palatalização no falar itaitubense não guarda relação apenas com o prestígio, mas com questões sociais mais complexas que serão discutidas quando da apresentação de outros grupos de fatores.

\subsection{Atuação da variável sexo sobre a variação de /l/}

Esse foi o segundo grupo de fatores selecionado pelo IVARB. Os pesos relativos obtidos para esse grupo vão ao encontro das expectativas. As mulheres apresentaram peso relativo mais alto do que os homens.

Tabela 2 - Variável sexo

\begin{tabular}{lcc}
\hline Fatores & Ocorrências & P. Relativo \\
\hline Homens & $653 / 485$ & .38 \\
Mulheres & $862 / 760$ & .59 \\
Input & - & .86 \\
\hline
\end{tabular}

Como já dito, a variante palatalizada é considerada como inovadora, não estigmatizada, prestigiada. Indício de que essa realização não é estigmatizada se encontra no fato de os indivíduos mais escolarizados terem 
favorecido significativamente sua aplicação e os não escolarizados a terem inibido. As mulheres receberam peso relativo igual a .59. Os homens obtiveram peso inibidor da regra, .38. Isso significa que há mais probabilidade de a regra ser usada entre as mulheres. As mulheres preferem significativamente a variante palatalizada.

Labov (1976) explica que há uma relação entre as variantes e os grupos sociais que as usam. O autor, ao tratar dos reflexos dos processos sociais sobre as estruturas linguísticas, assinala que a variação linguística é um indicador social. As variantes caracterizam os grupos sociais e esses, por sua vez, conferem a elas determinados valores. Ora, sabe-se que o valor conferido a uma determinada realização linguística não é emitido tomando-se por base critérios linguísticos, mas sociais. Muitas vezes uma determinada variante é considerada bonita ou boa se costuma estar na fala de um grupo privilegiado socialmente. Se um dado grupo é marginalizado pela sociedade, provavelmente as características linguísticas que marcam sua fala sofrerão também certo preconceito, cujo grau será proporcional ao grau de marginalidade atribuído ao grupo que a utiliza.

A princípio, devido à tradicional postura exigida da mulher pela sociedade, pode-se pensar que elas vão sempre priorizar, em sua fala, as variantes conservadoras, não estigmatizadas e de prestígio. Entretanto, como a relação entre língua e sociedade é complexa nem sempre isso se dá dessa forma. Nesta pesquisa, a escolha das variantes não se apresentou de forma comportada. Não se pode afirmar que aqueles três tipos de variantes (conservadoras, não estigmatizadas e de prestígio), que geralmente caracterizam as não marcadas socialmente, ocorrem na fala do gênero feminino em Itaituba. Talvez essa complexidade seja reflexo do fato de a palatalização constituir-se em uma variação inovadora que não carrega consigo um estigma social na localidade pesquisada. Ao contrário, seu uso está ligado aos grupos não marginalizados.

Tradicionalmente, os estudos de cunho sociolinguístico têm apontado as mulheres como indivíduos que encabeçam as variações e mudanças linguísticas quando essas não são estigmatizadas nos processos de variação estável. Isso é confirmado por Labov (1982). Mas o comportamento delas sofre alterações a depender do fenômeno que é avaliado. Scherre (1993), ao analisar a relação entre concordância nominal e gênero, assinala que a atuação das mulheres não é muito clara. Sua postura linguística depende das relações 
sociais construídas em dada comunidade. Assim, elas podem favorecer tanto variantes inovadoras como conservadoras. Oliveira (2002), ao estudar o apagamento do / r / em final de vocábulo, faz referência ao fato de as mulheres liderarem o processo de variação e mudança desse apagamento. Explica que a supressão do / r / final não é estigmatizada, diferentemente do que se percebe, por exemplo, para a supressão de -s, marcador de plural, variação estigmatizada. Callou (1979) afirma que os estudos realizados sobre o Português do Brasil revelam que as mulheres optam pelas variantes inovadoras quando elas não implicam estigma. As mudanças linguísticas são, geralmente, por elas encabeçadas, quando implicam certo prestígio. Na presente pesquisa, parece que a não estigmatização da palatalização tem tido significado para o favorecimento da variante palatalizada entre as mulheres. Elas receberam peso relativo igual a .59. Esse índice estatístico revela que elas favorecem de forma significativa a aplicação da regra.

O conhecimento do valor, significado de determinada variável serve de indício para a compreensão de outras variáveis. Utilizando-se desse pressuposto, pode-se entender melhor o resultado correspondente aos homens e mulheres desta pesquisa. Como já foi dito anteriormente, a variante palatalizada é inovadora e goza de prestígio em Itaituba. O significado social de $[K]$ está ligado aos grupos sociais que mais a utilizam. Labov (1982) explica que a estratificação social é um processo que se reflete na estrutura linguística. Se as mulheres e os mais escolarizados encabeçam a mudança de /1/, então a variante palatalizada se constitui a forma socialmente prestigiada. A variante alveolar, por sua vez, caracteriza o inverso. Labov (1982) explica, ainda, que os dados sociais dos informantes são de extrema importância para que se possa compreender a correlação entre determinados grupos e certas variantes linguísticas, bem como sua regularidade. Essa diferença de resultados entre homens e mulheres deve estar relacionada também a outros fatores de ordem social que se pretende discutir para refinamento da análise.

Conforme dito na metodologia deste trabalho, Itaituba foi e ainda é, embora apresente hoje menos atividade no setor de garimpagem, uma cidade garimpeira. O levantamento baseado em dados do IBGE mostra que, na década de 1970, o número de homens era, curiosamente, maior do que o número de mulheres nessa cidade. Isso se deveu às atividades desenvolvidas no garimpo. Grande era o número de nordestinos, especialmente maranhenses, que migraram para essa cidade, a fim de lá desenvolveram o 
cultivo do ouro e de outras pedras preciosas. Apesar de todos os informantes da amostra terem nascido na cidade e serem filhos de pais também nela nascidos, é possível que o convívio no garimpo tenha contribuído para que os homens usassem mais a variante alveolar. Ora, esse tipo de atividade é geralmente praticado por homens advindos de zonas rurais e com pouca escolaridade, de acordo com Silva (1997). Se as mulheres preferem o prestígio, devem favorecer a variante mais usada na zona urbana e entre os escolarizados ${ }^{4}$.

Por outro lado, as mulheres não tinham quase contato com os nordestinos que migravam para a cidade, pois, em geral, seu destino era a zona rural. Se a variante usada pelos nordestinos, de acordo com o levantamento bibliográfico realizado para o presente estudo, é a lateral alveolar [1], então, nesse espaço, era essa a variante mais praticada por esses falantes. Como o imigrante garimpeiro (nordestino) está intimamente ligado ao garimpo, talvez a variante alveolar [1] se constitua marca do grupo, os garimpeiros. Confirma isso o fato de os dois falantes mais idosos do corpus que desenvolveram atividades no garimpo, durante muito tempo, apresentarem, em sua fala, significativa ocorrência da variante não palatalizada. Essa classe, na Região do Tapajós ${ }^{5}$, tem-se mostrado bastante unificada no que se refere à defesa de seus interesses. Tanto é verdade que diversas vezes o governo já proibiu a extração do ouro em algumas localidades por causa dos problemas ambientais que provocam, mas sem sucesso, pois os garimpeiros sempre retornam às atividades. Isso pode ser constatado na avaliação que Rodrigues Filho et al. (1997) fazem da Associação dos Mineradores do Tapajós:

A AMOT, por sua vez, oferece serviços bastante variados a seus associados, como programas de assistência médica, informações nos diversos níveis e, também representa seus interesses, muitas vezes exercendo pressão política. Através do apoio à formalização institucional e do seu papel de 'advogada' dos donos de garimpo e

${ }^{4}$ Lopéz Morales (1989) apresenta exemplo de variante linguística que é rejeitada por caracterizar o falar da zona rural.

${ }^{5}$ Região em que fica localizado o município de Itaituba. 
garimpeiros, tem tido forte interação com diversas agências governamentais (RODRIGUES FILHO et al., 1997, p. 5).

A variante linguística se configura uma espécie de marcador de determinados grupos sociais. Assim, embora a aplicação geral da regra de palatalização tenha recebido input igual a .86, dados sociais referentes aos homens revelam que a baixa probabilidade da regra em sua fala pode ter relação com a marcação do grupo, os garimpeiros. A variante alveolar estaria simbolizando valores sociais de um subgrupo específico em Itaituba.

\subsection{Cruzamento entre variáveis: escolaridade e sexo}

A linguagem é uma forma de comportamento social e sua análise rigorosa contribui diretamente para o conhecimento da estratificação social. O refinamento na análise das variáveis pode oferecer mais informações para o entendimento dos resultados estatísticos obtidos. Por isso, realizou-se cruzamento entre as variáveis sociais.

A partir da interação entre dois grupos de fatores já existentes, foi criado o grupo de fatores escolaridade x sexo. Tinha-se como finalidade verificar a interferência da escolaridade sobre os dois gêneros. Os resultados dessa interação estão dispostos na Tabela 3:

Tabela 3 - Cruzamento entre escolaridade e sexo

\begin{tabular}{lcc}
\hline Fatores & Ocorrências & P. Relativo \\
\hline MA & $188 / 287$ & .23 \\
MB & $157 / 221$ & .27 \\
MC & $140 / 145$ & .81 \\
FA & $232 / 298$ & .34 \\
FB & $312 / 323$ & .82 \\
FC & $216 / 241$ & .58 \\
Input & - & .88 \\
\hline
\end{tabular}


Os resultados fornecidos pelo IVARB confirmam a seleção dos grupos escolaridade e sexo, quando da primeira rodada realizada por esse programa. Esses grupos foram, respectivamente, o primeiro e segundo grupos selecionados pelo programa de regra variável. O grupo de fatores escolaridade versus sexo foi o primeiro grupo de fatores selecionado durante a rodada em que foi realizado o cruzamento entre variáveis.

Os resultados da Tabela 3 revelam que a escolaridade atua de forma significante sobre a palatalização de / $1 /$ nos dois sexos. Os homens que não apresentam instrução e aqueles que têm o ensino fundamental são os que desfavorecem a aplicação da regra. Tem-se uma escala crescente em que mais escolaridade implica mais palatalização. Os homens mais escolarizados (MC) favorecem de forma muito significativa a regra, com peso igual a .81. Os dois outros grupos a inibiram, com pesos relativos iguais a .23 , para não escolarizados (MA) e .27, para o ensino fundamental (MB). Assim, em termos gerais, de acordo com os resultados referentes à variável sexo (cf. Tabela 2), os homens desfavorecem a regra, mas os homens mais escolarizados são os que menos contribuem para sua inibição, demonstrando que a variável escolaridade é mais determinante. Esses resultados parecem estar ligados à escolaridade, mas também ao grupo a que parte desses homens pertence. Do total de 18 homens entrevistados para a pesquisa, dez desenvolveram atividades garimpeiras. Desses dez, seis integram o grupo de não escolarizados; os outros quatro só apresentavam o $1^{\circ}$ grau. A fala desses informantes deve ter contribuído para o desfavorecimento da variante palatalizada entre os homens que apresentavam baixa ou nenhuma escolaridade.

As mulheres que têm mais instrução apresentam probabilidade favorável à regra. Tem-se, .82 e .58 , respectivamente, para $1^{\circ}$ e $2^{\circ}$ graus. Já as que não estudaram inibiram a palatalização. $O$ fato de as mulheres com Ensino Fundamental terem favorecido mais a regra do que as mulheres com Ensino Médio causou surpresa, pois esperava-se que as mais escolarizadas apresentassem probabilidade mais alta. Talvez esse resultado esteja ligado à sobreposição de outro fator que, no presente estudo, não se consegue apontar com segurança. Pode ser que informações constantes da ficha dos informantes deem uma pista sobre isso, mas ressalta-se que se apresentam apenas hipóteses a seguir. Das seis informantes FC (mulheres com $2^{\circ}$ grau), quatro trabalhavam no setor de Educação. Isso pode ter diminuído o uso da variante palatalizada 
e aumentado a utilização da forma que é praticada na escrita entre as FC, todas professoras. De qualquer forma, pode-se dizer que as mulheres escolarizadas favoreceram a palatalização.

O Gráfico 1 ajuda a visualizar o distanciamento de resultados entre os dois gêneros.

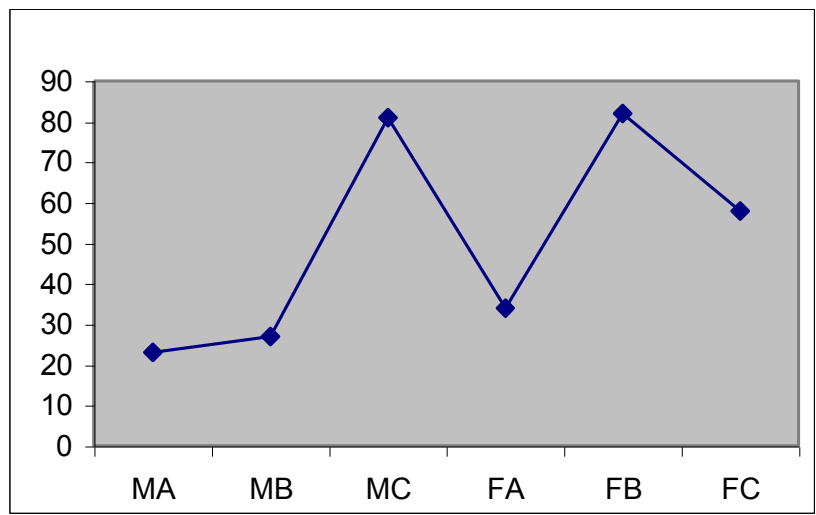

Gráfico 1 - Cruzamento entre escolaridade e sexo

Note-se que, entre os homens, tem-se uma escala crescente em direção ao segundo grau (MA, MB, MC), tendo-se uma significativa subida quando se chega a MC. Entre as mulheres não se percebe uma linha crescente em que se possa relacionar mais escolaridade a mais uso de palatalização, exatamente como se faz para os homens. O ponto mais alto da regra é encontrado entre as mulheres com o Ensino Fundamental (FB). Essas mulheres palatalizam, com uma pequena margem de diferença, tanto quanto os homens com Ensino Médio (MC). Esses resultados explicam, de forma mais refinada, por que a escolaridade foi a primeira variável selecionada pelo IVARB.

\section{Considerações Finais}

As variáveis sociais apresentam forte atuação sobre a variação de /1/. Das três variáveis sociais submetidas ao programa de regra variável, duas foram selecionadas: escolaridade e sexo. Posteriormente, o cruzamento 
entre essas duas variáveis confirmou a referida seleção, já que a variável que resultou do cruzamento também foi selecionada e apresentou input superior aos demais grupos de fatores, o que revela o peso dos fatores sociais sobre o fenômeno em estudo. Os mais escolarizados palatalizam mais do que os menos e os não escolarizados. Quanto ao sexo, pode-se dizer que as mulheres são as que preferem a palatalização, porém cabe ressaltar que os homens mais escolarizados são os que menos contribuem para a inibição da palatalização. Isso ficou confirmado quando da análise dos dados referentes ao cruzamento entre variáveis. Por fim, os altos inputs relativos à palatalização, acima de .85, apontam a regra como tendência no falar de Itaituba.

\section{Referências}

AGUILERA, V. de A. Atlas Lingüístico do Paraná. Curitiba: Imprensa Oficial, 1994.

BHAT, D. N. S. A general study of palatalization. In: GREENBERG, J. S. (Ed.). Universals of human langage (Phonology, v. 2). Stanford, CA: Stanford University Press, 1978. p. 47-92.

BLOOMFIELD, L. Language. New York: Henry Holt, 1933.

BRASIL. Ministério das Minas e Energia. Programa de Integração Mineral no Município de Itaituba. Belém, 1996.

CALLOU, D. M. Variação e distribuição da vibrante na fala culta do Rio de Janeiro. 1979. Tese (Doutorado em Linguística) - Universidade Federal do Rio de Janeiro, Rio de Janeiro.

KOCH, W.; ALTENHOFEN, C. V.; KLASSMANN, M. S. (Org.). Atlas Lingüístico-Etnográfico da Região Sul do Brasil-ALERS. v. 2: Cartas fonéticas e morfossintáticas. Porto Alegre: Editora da UFRGS; Curitiba: Editora da UFPR; Florianópolis: Editora da UFSC, 2002.

LABOV, W. Sociolinguistique. Paris: Édition de Minuit, 1976. 
LABOV, W. Building on empirical foundations. In: LEHMANN, W; MALKIEL, Y. (Ed.). Perspectives in Historical Linguistics. Amsterdam: John Benjamins, 1982. p. 17-92.

LOPÉZ MORALES, H. Sociolingüística. Madrid, Gredos, 1989.

MIRANDA, J. G. de et al. Atividades garimpeiras no Brasil: aspectos técnicos, econômicos e sociais. Rio de Janeiro: CETEM; CNPq, 1997.

MOTA, J. Variantes palatais do português do Brasil. In: RUFFINO, G. Atti del XXI Congresso Internazionale di Linguistica e Filologia Romanza. Università di Palermo. Centro di studi filologici e linguistici siciliani. 1995. p. 475-483.

OLIVEIRA, M. B. de. Manutenção e apagamento na fala de Itaituba-PA. 2002. Dissertação (Mestrado em Letras: Linguística e Teoria Literária) Universidade Federal do Pará, Belém.

OLIVEIRA, M. B. de. Palatalização da lateral alveolar /l/ em posição prevocálica em Itaituba-PA. 2007. Tese (Doutorado em Letras e Linguística) Universidade Federal de Alagoas, Maceió.

OLIVEIRA, M. B. À guisa de uma explicação sociolinguística para a acentuada palatalização de /1/ em Itaituba-PA. Amazôninica - Revista de Antropologia, n. 2, p. 220-248, 2010.

OLIVEIRA, M. B. et al. Imagens preliminares da realização variável de /1/ prevocálico no estado do Pará. Signum: Estudos de Linguagem, n. 12, v. 1, p. 257-278, jul. 2009. Disponível em: <http://bit.do/cWsSG>.

RODRIGUES FILHO, S. et al. Garimpo e inclusão social no Brasil: dois estudos de caso. Rio de Janeiro: CETEM, 1997.

SCHERRE, M. Reanálise da concordância nominal em Português. 1993. Tese (Doutorado em Linguística) - Universidade Federal do Rio de Janeiro, Rio de Janeiro.

SILVA, A. P. Projeto Itaituba: programa de desenvolvimento de Tecnologia Ambiental. Rio de Janeiro, CETEM; CNPq, 1997. 
WEINREICH, U.; LABOV, W; HERZOG, M. Empirical foundations for a theory of Language change. In: LERMANN. W.; MALKIEL, Y. (Ed.). Directions for Historical Linguistics. Austin: University of Texas, 1968. p. 95188.

Recebido em: 27/05/2015 Aceito: 20/10/2015 